\title{
Teaching English to Young Learners-A look at Sudan
}

\author{
Dr Josephine O’Brien \& Dr HalaSalihNur
}

\begin{abstract}
Teaching of English to young learners has grown considerably as a business in the past two decades. Psychological, cultural and economic factors all play a role in influencingthe decision to teach English to children.While young learners share many commonalities, abilities and characteristics, factors such as a country's language policy, traditional relationships with the target language, and in particular available educational resourcesand the willingness to devote these to the learning of a second language make each teaching and learning situation different. Educational resources include materials, teacher training and the provision of a healthy educational environment in which effective teaching and learning can take place. The current paper considers a situation where the teaching of English is being revived in general and in particular to young learners. The work is based on a recent workshop, (April 2014), with a selected group of teachers in the University of Khartoum and explores some of the challenges and issues facing teachers of English to young learners; these include resources, environmental challenges and teacher training.
\end{abstract}

\section{Introduction}

It could be argued that the teaching of English to young learners is the most major industry to emerge in the business of teaching English to speakers of other languages in the past two decades (Nikolov\& Curtain, 2008; Espinosa, 2008). While the rationale for providing second language classes to learners in their early years is primarily psycholinguistic, factors such as gaining access to the global economy and technology are also important considerations. All young learners go through many of the same stages of development as indicated in Piaget's work on child development, while at the same time, as illustrated in the work of Vygotsky (1978) and Bruner (1966), socio-cultural influences play an important role in how learning progresses. Therefore, any evaluation of programs that offer language training to young learners must take all aspects of the process into consideration. This means a critical and constructive evaluation of not just the material provided for courses but also assessment of the teaching and learning environment, teachers' and learners' perceptions of the process and the classroom environment where learning takes place (Cameron, 2001). The current paper explores the teaching of English to young learners in a Sudanese context and attempts to position the research within the theoretical framework of influential theories of the $20^{\text {th }}$ century that have played a major role in shaping many education programs worldwide. Through the lens of a group of teachers of young learners in the Khartoum area, the classroom environment, strengths young children bring to the class, environmental constraints that present challenges in teaching English to young learners in an environment such as Sudan are exploredbased on a two day workshop, focused micro teaching and a questionnaire at the conclusion of the workshop.

\section{a. General Theoretical Considerations}

\section{Literature Review}

Teaching English as a second language to young learners requires knowledge of a wide range of topics including child development theories, teaching techniques that include classroom management and materials development suited to young learners along with a wide range of personality features and knowledge of culture and family circumstances. Developments in child psychology over the past century that have influenced all aspects of educationare first considered, followed by a discussion of issues directly related to teaching a second language to young learners. These factors are then revisited in the discussion around teachers' perceptions of teaching English to young learners in a Sudanese context.

Three psychologists of the $20^{\text {th }}$ century: Piaget, Vygotsky and Bruner played a profoundly influential role in the development of theories on how children learn and factors that facilitate learning. Piaget (1896 1980 ) is probably the best known as his seminal work (1928) undertook a systematic study of how the human mind develops. He concluded that, contrary to accepted beliefs, children's thinking differs fundamentally from that of adults.Learning, according to his theory, takes place when we are faced with new situations that can cause disequilibrium; in order to recover equilibrium, the mind must assimilate and accommodate new information and add new skills. His theory consists of three essential components: schema which Piaget (1952) defined as "a cohesive, repeatable action sequence possessing component actions that are tightly interconnected and governed by a core meaning" (quoted in Tuckman\&Monetti, 2010, p. 46), in other words basic knowledge blocks organizing what the child is learning and creating representations of the world which the child can understand and deal with; adaptation that involves equilibrium, assimilation and accommodation, which 
happens when children have to deal with new information and thirdly the various stages of learning. For Piaget, the stages children go through are universal moving from the sensorimotor (0-2 years), preoperational (2-7 years), concrete operational (7-11 years) and formal (11 onwards). His argument that these stages must occur in this order gave rise to the belief that certain concepts should not be taught until children have passed that cognitive developmental phase, an aspect of his theory that has been subjected to much criticism in curriculum development. (McLeod, 2009)

Unlike Piaget, Vygotsky (1896-1934) stressed the fundamental role of social interaction in the development of children. He argued that, "learning is a necessary and universal aspect of the process of development, culturally organized, specifically human psychological function." (1978, p. 35). In other words, social and cultural contexts are vital factors in children's development and for Vygotsky, social processes play a major role in the development of higher mental processes, thus contradicting Piaget's view of very formalized universal stages of development that all children must go through in a specific order. Vygotsky (1978) coined the phrase Zone of Proximal Development (ZPD), which he defined as "the distance between the actual developmental level as determined by independent problem-solving and the level of potential development to determine through problem-solving under adult guidance or in collaboration with more capable peers." (p. 33). With this concept, Vygotsky acknowledges that there are elementary mental functions common to all, which he labels as four: attention, sensation, perception and memory but how these develop depends very much on the socio-cultural and educational habitus of beliefs, values, and cultural tools that help intellectual development. The educational environment is paramount as learning takes place according to the ZPD with the guidance of a skilful adult, or older child referred to in Vygotskian terms as the MKO or More Knowledgeable Other and through collaboration with one's peers. To Vygotsky, language is fundamental to cognitive development, a factor not emphasized by Piaget and the development of thought is intricately linked to that of language. In fact, perhaps the greatest tool the human has is that of language as it is the medium through which information is transmitted to children and in itself is a tool of adaptation both through social dialogue and private speech with oneself. Vygotsky, thus, places the emphasis firmly on the social, cultural, educational and linguistic environment of the child. (Vygotsky, 1978)

Jerome Bruner (b. 1915) further developed some of Vygotsky's ideas and has contributed greatly to the whole field of cognitive theory in education. Bruner (1966) argued that the aim of education is one of creating autonomous learners who not only have the ability to think critically, problem-solve, organize, but also invent. He identified three modes of representation by which knowledge is stored and encoded in memory. The first is enactive in which the child stores "action based information" in the memory and learns motor actions and responses, the second iconic in which visual representations of knowledge are stored and finally symbolic when knowledge is coded as language, thus permitting much more manipulation of stored information and ability to deal with concepts. Bruner (1960) outlined the implications of his theory in "The Process of Education" in which he argued that learning is an active process with students developing the capability of constructing their own knowledge. Like Vygotsky and contrary to Piaget, he argued that one does not have to wait for the child to go through all the phases of development: "We begin with the hypothesis that any subject can be taught effectively in some intellectually honest form to any child at any stage of development" (Bruner, p. 31). To achieve this, he introduced the notion of the spiral curriculum in which complex ideas can first be presented in a simplified way and then on through gradually increasing difficulty. Discovery learning is also fundamental to his theory,giving rise to the prevailing constructivist approach in curriculum design today. This approach views the teacher as facilitator who presents lessons that aid the discovery and not the memorization of knowledge.

Most modern education programmes have been influenced to some degree by the work of these three psychologists. Whilethere were differences between the three particularly on stages of child development, Piaget's belief that assimilation and accommodation can only occur when the learner is active is fundamental to all educational situations today. In addition to the importance of an active learner,Vygotsky and Bruner argued that environmental factors play a vital part in the speed and effectiveness of educational growth and development. Both emphasised the role of language in the cognitive growth of the child as well as the importance of support from capable adults in the learning environment as illustrated in Vygotsky's zone of proximal development and Bruner's notion of scaffolding. These are major considerations in the physical, affective and cognitive elements in the environment of young learners.

\section{b. Relevance of theories to English Language Teaching:}

While these psychological theories focus on learning in general,they have also had a profound influence on the teaching and learning of foreign languageto people of all ages. The teaching of English as a second language to young learners, as pointed out already, has grown considerably but there is still not universal consensus on whether initiating the teaching of English to children at a young age is the most productive time. Jayne Moon (2005) in her plenary address at a conference entitled 'First Steps to Success' outlined some of the arguments presented to justify introducing English as a second language to young learners. One factor is the 
belief that the younger children are when they begin to learn a second language the better as according to Lenneberg's Critical Hypothesis Theory (1967), children are likely to be more successful in learning another language if they begin before the age of puberty. This is still a contested theory and as Moon points out there is evidence to the contrary; she refers to McLaughlin (1992) for example who pointed out that adults and adolescents are much more effective grammar learners than young learners. However, it is generally accepted that with teachers fluent in the target language, young learners are much more likely to acquire correct pronunciation as the organs of articulation are still developing so mastering the new sounds seems not to be challenging.

Moon (2005) raises other concerns when introducing young learners to second language learning. She points out that children learn in a very different way to older children and adults. Mostly, they are concerned with meaning and not form; they are not self-regulated and can get bored quickly. Therefore, a variety of activities are very important, as is the personality of the teacher who has a very powerful influence on young learners and their feeling for the subject. Nikolov\& Curtain (2000) refer to teachers as the "most important stakeholders" in the discussion on teaching English to young learners. The vital questions, they point out, are those of the teachers' "proficiency and the appropriacy of their methodology" as the young learners are greatly affected by their teachers. Competent teachers of young learners need fluency in the target language as well as good communication skills, confidence in their own abilities and knowledge of patterns of development in children as outlined in the discussion above. In terms of methodology, Nikolov\& Curtain advocate a focus on meaning, an approach that puts task and content to the fore, active learning and development of independent learners (p. 7). Moonalso argues that what is more important than the age at which children begin learning the L2 is having suitable conditions. Basing her arguments on the work of Met and Rhodes (1990), she suggests that, as they do not have well developed memories, children need short and frequent learning sessions of around $30-40$ minutes a lesson several times a week Thus, it is clear that, as already suggested by the educational theorists, the nature of the child, the ability of the teacher, the learning environment and methodology are all vital elements in the teaching and learning process.

Teachers of young learners undoubtedly need courses, guidelines and knowledge on the psychology of young learners, as this knowledge will affect everything they do in the classroom.Literature abounds on the practical application of many of the theoretical ideas to the classroom situation and several websites provide ready-made activities for use in the classroom butone factor that can affect the implementation of many of the suggested ideas is that of the role of the teacher (Garton, Copland \& Burns, 2011;McLaughlin, 2012); in some traditional cultures the role of the teacher is viewed as the knowledge giver and the learner as the knowledge receiver with the expectation that children listen while the teacher talks (Mohr \& Mohr, 2007). The children may memorize for an examination and parents are happy if the child receives a good grade. Thus, the distance between teachers and students is wide and unlikely to encourage trust and dialogue; the focus in such situations is often of maintaining control with little time or attention given to involving students in meaningful activities. This brings us to the context of the current paper: Sudan where teaching and learning are classified as happening in a traditional educational context (O’Brien, 1988, 2013; GumaaSiddiek, 2011)

\section{c. Sudanese English language teaching context from a historical perspective}

Education and particularly the teaching of English as a foreign language in Sudan today at any level cannot be evaluated by focusing on psychological and linguistic theories only. Considerations such as the prevailing political ideology and how this impacts on how English and western culture in general are viewed, affective factors that may result from these ideological issues, the relationship facilitative or otherwise of the L1 Arabic to the target language and economic factors that impact on education, class size and teacher training all play a part in the learning process.

Sudan has had a complex relationship with the English language over the years. As a former British colony, the country adopted English as the medium of instruction initially after independence as English was the "language of earning a living" (El Tigani, 1966) and was considered essential for development especially in science and technology and a key to progress, possibility and prestige. However, the developmental goal of increasing overall literacy levels resulted in the transition to Arabic as the medium of instruction in schools, resulting in mass expansion of education and naturally, increases in class sizes. Taha (1980) pointed out that the opening of educational opportunities to the masses resulted in a rapid increase in the number of students without a corresponding increase in teacher training and preparation of materials and methodology. He pointed in particular to the "failure to assess traditional approaches to teaching during the process of expansion that must be considered primarily responsible for such decline in standards as there has actually been." (p. 43) It was reported that crowded classrooms and shortage of equipment were permanent features of most schools. Research (O'Brien, 1988) concluded that 40 per cent of students of English at secondary schools were in classes of over 60 while 90 per cent had 50 students or more in the class. Many did not have an individual textbook and such an 
over-crowded, ill-equipped context created logistical problems when efforts were undertaken to shift the focus from a teacher dominated to a student centered methodology. The same was true in primary schools.

Changes in the educational ladder and with Arabic as the main medium of instruction and the consequent reduction of hours allocated to English language instruction resulted in a drastic drop in standards. Through the decades following independence, criticism of the abilities of English Language teachers and the paucity of teaching materials continued to mount (Taha, 1980). Several committees made a range of suggestions but little practical action was taken. While students' desire to learn English remained high as university education and advancement in the professional world depended on English language competency, shortage of funds, books and teaching equipment, decentralization, provincialism and poor teacher training programs resulting in the recruitment of teachers with inadequate skills aggravated the declining standards. In the context of Sudan, vagueness surrounded the teaching of English in the secondary schools, as there was no immediate communicative objective for the language in everyday society (Abdel Mageed, 1985).

\section{d. English language in Sudan today}

Today as in the past,the textbook and completing its contents is still viewed as the main objective in the teaching of English in spite of much discussion about the different variables involved in the teaching and learning process. Taha (1980) had already referred to three important elements in the equation: materials, teachers and teaching style, students and learning style. The traditional teaching and learning style at the time was that of the perception of education as the transmission of information in which the teacher is the narrator or transmitter and the students are the passive recipients, a situation that was described by Friere (1972) and his heirs the proponents of critical pedagogy today (Kincheloe, 2008) as one similar to banking as Friere argued the act of teaching was no more than the act of depositing (45) "in which the students are the depositories and the teacher is the depositor ...... This is the banking concept of education, in which the scope of action allowed to the students extends only as far as receiving, filing and storing the deposits." Revision of course material in any situation is one part of the equation but not enough as any course is only as good as its medium. Any assessment of a programme and analysis of performance involves a triangular relationship that involves all players. Courses have been tailor made over the years for the teaching of English in Sudan but there are still worrying issues to be resolved. From the 1980s on, many teachers have not been English language graduates and have had little or no training. From the initial stages in the setting up of a national educational system in the country, reference was made to the importance of teacher training (Mohammed \& Abdel Ghani Ibrahim, 2009);however, classroom methodology has continuedto be traditional with the focus in language learning on grammar rules rather than communication. The method of assessment has continued to be testing of knowledge about the language in a final examination rather than use of the language. Most of the teachers still do not have not have any facility to practise English outside of the four to five hours when they are actually teaching the language(Author's discussion with teachers). This continues to present a major challenge tothe development of their English language competence and professional confidence (Baffoka, 2006).

It could be argued that teachers lack three fundamental requirements for effective teaching: a reasonable level of competence in English and training in and understanding of various methods of teaching the four language skills in the classroom and the ability to adapt methods and materials to their own classroom environment. The involvement of teachers in decision making and in curriculum development and materials writing is vital as a way of developing professional empowerment and building teacher self confidence. Essential to teacher's ability to select, modify and adapt materials to classroom contexts lies a broad understanding of principles that inform materials development and methodology choices. Consequently, teachers continue to be unaware of the required pedagogical and methodological issues underpinning courses, the rationale for the course and are not informed of what students have learned prior to arriving in their class. Teachers' opinions are not sought on the development of courses or examinations.(Discussion with teachers)

One of the concerns of the 1989 government was the ideological aspect of the use of English as a medium of instruction and the impact western values as delivered through English might have on Sudanese traditional and Islamic values. A decision was made to remove English as the medium of instruction in the universities. While this is perfectly within the mandate of any legitimate government, change in language policy generally takes time and planning and the decision of the government was interpreted as more political than educational and generally viewed as not well planned. Whatever the motivation, this decision has had profound implications for the state of English language in Sudan over the past two decades and on the standard in schools where English is taught as a school subject and at university where English is still a partial medium of instruction in medicine and sciences. A decision has now been taken by the Ministry of Education with funds from the World Bank to refocus attention and resources on the teaching of English in the schools beginning with young learners for whom a new curriculum and syllabus is currently being designed. One book of a new series entitled SMILE (Sudan Modern Integrated Learning English) has already been completed. However, the factors 
outlined above on low competency of teachers, few if any training courses, limited resources continue to present major challenges.

\section{Methodology for data procurement:}

While a number of factors or constraints have been identified above, the current paper discusses the situation from the teacher perspective only based on teacher attitudes and challenges gauged after a recent twoday workshop (April, 2014) in the University of Khartoum on teaching teachers of young learners. The workshop emerged from discussions between the current researchers on the training needs of teachers of young learners given that a new syllabus and textbooks that focus on more up-to-date approachesto language teaching is being developed with the support of the Ministry of Education, World Bank funds and under British Council Management. The workshop was planned for a time when all participants and the trainers were free to participate and was run on a purely voluntary basis with numbers limited to 20 participants because of facilities. The first day of the workshop was devoted to exploring teachers' strengths in terms of theoretical knowledge brought to the teaching process, attitudes and interests in teaching and learning and general competency in English. Fundamental theories of early childhood education as laid out in the literature review section were included as were more practical aspects of teaching young learners. The approach taken was that of creating a non-threatening environment in which participants could communicate their knowledge, questions, and concerns related to the teaching situation. Instead of a lecture approach, participants were given hand-outs with questions to discuss in pairs and groups and this led to discussions on topics while at the same time demonstrating a possible methodological approach that could be applied in the classroom. Such an approach also allowed participants to get to know each other and to share narratives about their teaching situation. As the workshop proceeded, relevant theoretical points were introduced and discussed. More confident participants were quickly identified and groups were formed so as to maximise communication by partnering the linguistically strong with the less strong. In all teacher training with non-native teachers, an element of language remediation is important and though time was restricted an effort was made to provide useful information on the English language system; some participants have very little opportunity to speak or practise English and admitted to relying quite a bit on Arabic to explain texts to students. On the second day of the workshop, participants formed into groups of four and prepared and presented a lesson, commented on how they had decided on the topic and what they had done to prepare and the materials needed. The other participants along with the presenter provided positive comments and feedback. The workshop concluded with a questionnaire feedback, the output of which is discussed in the following section.

\section{Building an initial profile of Sudanese teachers of young learners}

Contexts, environmental constraints, views and attitudes of the participants on a number of topics as laid out in the questionnaire (see Appendix) are discussed in the following paragraphs.

\section{i. Participants: (Q. 1)}

While education at all levels involves a minimal fee, schools classed as government schools involve payment of a very modest fee while private schools are more expensive. This can affect many aspects of administration, class size and approach to teaching and learning. Of the twenty teachers who participated in the workshop, sixteen work in government and four in private schools. (Q. 1) ii.Responses to Q.2 on resources indicated that schools vary in the amount and type of resources available. Most government schools have only blackboards and white chalk, the traditional resource of all classrooms. Teachers themselves provide some realia for the language classroom along with flash cards and posters. Private schools are better equipped with white boards and coloured board markers, flash cards and cassette players. iii. Class sizeOne of the educational environmental issues faced by many developing countries with limited resources is class size and as indicated by the participants here, class size can be challenging as in government schools, class size varies from 40 to 120 pupils while in government schools numbers are lower with from 20 to 45 pupils per class.

\section{iv. Number of classes taught in the week and length of period $(Q .4 \& 5)$}

While the number of English periods taught by each participant varies, students have six periods of 45 minutes a class per week. Teachers may have other subjects to teach and other duties in the school. All but two of the teachers in government schools reported enjoying their classes very much. The two exceptions agree that they enjoy the classes sometimes.

\section{v. Challenges faced by teachers teaching young learners $(Q .8)$}

The main challenges faced by teachers in government schools are class size, the layout of the physical environment often resulting from over-packed classrooms, limited resources, student motivation, lack of support from problem students' families and above all lack of teacher training courses and lack of teacher 
empowerment. Similar problems exist in private schools with the main highlighted ones being communication with families, dealing with students with special needs, classroom management and inadequate classroom environment.

\section{vi. The perceived strengths of the learnersand importance of active learners $(Q .9 \& 10)$}

While teachers indicated that they face many difficulties in the learning environment and in the support or lack of they receive from authorities, their perception of their learners is overall positive. The main perceived strengths of young learners include the nature of the learners themselves and the openness they bring to the classroom, their curiosity, adaptability, flexibility, imagination, their willingness to learn and their love of stories and song. Teachers overall were enthusiastic about the need to encourage active learning and participation in the lesson but all pointed to the classroom environmental constraints which limits movement and possibility of group activities.

vii. Classroom management issues (Q. 11)Teachers in both government and private schools face some classroom management problems especially when students need more support. Some consider that English is too difficult a subject for young learners particularly when there is little or no support from home. Some schools require students to sit quietly in their desks and this makes the question of movement, pair and group work impossible. A couple of teachers noted that occasionally they use physical punishment to get students to sit quietly.

viii. Value of the workshop and main points of interest (Q. 12\&13)All participants agreed that the workshop was beneficial. They pointed in particular to the theoretical ideas and how these are manifested in a practical way in the classroom. The concept of scaffolding, active learners, differences between learners and how to deal with these and the various approaches to teaching young learners discussed over the two days were all highlighted as being of interest and benefit. While many complained of the lack of resources, a vibrant discussion developed around the idea of preparing locally made materials and using local resources including photographs of Sudanese cultural aspects to develop vocabulary. Another very important point raised was the opportunity provided to discuss issues related to their classroom practice in a non-threatening way and the sharing of ideas and narratives of each other's situations.

\section{viii. Possibility or not of applying ideas to teaching situation (Q. 14\& 15)}

All participants agreed that they would like to apply some of the ideas discussed in their own classrooms. However, for all teachers in government schools, any ideas related to technology are unworkable as schools are not equipped. As pointed out already, most schools have only blackboards and chalk. Additionally, activities that require movement around the classroom would be challenging to complete given the overcrowded nature of many of the classrooms.

\section{ix. Attending another workshop (Q. 17)}

All teachers agreed that the workshop was very motivating and beneficial and all would be happy to attend further workshops.

\section{a. Teachers}

\section{Discussion around teachers' responses}

Teacher training in the past was viewed as an essential element of any education development in Sudan and for this purpose special teacher training institutes were established in geographically strategic areas around the country in which the training of teachers took place throughout the 1960's, 70's and 80's. These were located in the White and Blue Nile Provinces, Northern and Western Sudan and Khartoum and in the universities of Khartoum and Gezira in Wad Medani. Prior to the change of government in 1989, expatriate teacher trainers as well as Sudanese specialists were involved in teacher training. Many of the teachers trained in these centres have left Sudan for the Gulf countries; with the change of government some left for political reasons, all who leave now do so for economic reasons.

Frequently, today those who decide to become teachers do so because they fail to be accepted for any other university program. Gumaa-Siddik(2011) reports that $90 \%$ of the trainee teachers participating in his course in the College of Education in Khartoum stated that they ended up doing an education course because their grades in the Sudan School Certificate were too low to qualify them for any other faculty in the university. With such a de-motivated approach and low level of academic performance among teacher trainees before they even enter the classroom, it is unlikely that such candidates will motivate students. Mohammed (2009) expressed deep concern about the state of teacher training in Sudan. Having summarized the major contribution made by teacher training institutes in the past, he goes on to identify the many difficulties facing the training of teachers today. He is extremely critical of programs for training teachers in the colleges of education and pointed out that they had no particular vision or mission, lacked administrative organization and consisted of 
staff who themselves were unqualified to train teachers. He cites statistics that show no college of education has sufficient or adequately trained staff. Colleges vacillate between preparing trainees, attempting to interact with the community and carrying out educational research, none of which they are doing effectively. Mohammed also noted that these colleges delivered a theoretical syllabus and did not provide trainee teachers with the opportunity to practice what they were studying or get constructive feedback on how they managed the classroom. In addition, the actual language ability of trainees was low and most undertook the training only to find employment. Trainees also lack development in independent learning skills and consequently would not be able to develop these skills among their learners in the classroom. The picture as presented by Mohammed is quite bleak.

Though the recent workshop took place over a two-day period only, the concerns raised by GumaaSiddik and Mohammed were clearly visible. A few teachers reported attending some theoretical workshops at British Council but all pointed out the fact that this was the first time they had the opportunity to try to apply these theories to practice and receive constructive feedback both from their peers and the trainers. Many have never attended any courses that discuss educational theorists and for these the information on Piaget, Vygotsky and Bruner was completely new. Prior to this workshop, they had had little or no discussion of the important educational theories and how these impact on classroom performance. While teachers pointed out that they have visits from inspectors, these are rarely of any real value and little or no discussion takes place on the content or methodology of their lessons. Consequently they are left to their own devices and often feel they have been completely abandoned.

Two issues were of major concern: the language proficiency of some participants and the knowledge of any theoretical work within which to frame teaching in general and in particular the teaching of young learners. Both factors are extremely worrying; the first reflects the serious decline in knowledge of, exposure to and functional use of English in Sudan and the secondgenerates concern because as pointed out in the literature review children learn in a very different way to adults or older children and they are not motivated by examination pressures or results. Many participants did not seem to be aware of these differences, the need for active learning, and the provision of the necessary scaffolding for young learners; they also mentioned the pressure from administration to keep children sitting quietly in their places. This allows little space for the development of active and independent learners.

Teachers are a vital resource in the learning triangle of students, teachers and materials and it was rewarding to experience the appreciation of these participants when given the chance to express their views, concerns and demonstrate their work in a class simulation. Some participants were reluctant initially and had to be encouraged but all participated and feedback indicates that they found it a very rewarding activity. Ability to give and receive criticism is part of the maturing process as teachers and again this may be an element that has to be developed and demonstrated. One comment in the feedback questionnaire suggests that it is sometimes teacher training in all its dimensions that needs serious development. The teacher wrote:"Many Sudanese teachers don't like their colleagues' negative comments, especially advice and comments from a young teacher like me. Moreover the lack of training is a big issue not only for teachers but also for their superiors. We have many resources, aids and materials but teachers don't know how to use them." The suggestion here is that teachers simply do not know how to operate a classroom irrespective of the resources. The challenges faced by teachers are not always in the classroom and the demotivation begins with the job itself. One participant pointed out that "teachers are forced to work in different schools. They are tired and not motivated; collecting money is an issue. They receive a bad salary so they leave school after the lesson for another school searching for money. The worst salaries are given to school teachers and those in education in general."

Workshop participants were particularly impressed with the theoretical knowledge delivered and the relevance of this to the teaching and learning process. Aspects of methodology discussed were also rated as very relevant along with discussion on how young learners learn and the importance of involving the children in an active manner. Opportunities to discuss issues related to teaching and learning as well as the opportunity to prepare and collaborate with colleagues in the delivery of a lesson were all listed as highly beneficial.

\section{b. Students}

While there was no opportunity during the workshop sessions to visit schools as all were on holidays, much discussion revolved around the classroom dynamics, which of course included the students. Situations vary very much from school to school as socioeconomic factors play a huge role in numbers, motivation, available materials and resources and attitudes of students. The educational system in Sudan is still very much focused on summative assessment i.e. a final examination, the results of which decide whether or not a pupil carries on to the next level. From the discussion with workshop participants, it emerged that parents very often affect how the course unfolds as there is huge pressure from the first day for pupils to show tangible results i.e. writing activities for which they are graded. This was seen as a major obstacle in changing the style of teaching and learning and even the introduction of the first book of the new course SMILE as the focus in the book for 
the first year (Grade 3) is on speaking and listening. It was pointed out that parents need some education on how the teaching of young learners occurs and the subsequent learning process so that there is not so much pressure on pupils to bring home written homework. There was general agreement that pupils would benefit much more if they were given the time to practice the sounds, repeat, sing songs and play games so that a good foundation was laid for the basics of the language.

Apart from the expectations of the course particularly from parents, participants generally had a very positive impression of young learners and identified strengths common to young learners worldwide. These included an openness and flexibility, imagination and lack of self-consciousness in practicing sounds, singing along, playing games and telling and listening to stories. These are all the characteristics that make for good young learners. However, the major challenge facing teachers is the classroom environment. Some of the difficulties faced are class size, up to 120 students in a class, fixed furniture so there is little or no scope for movement, pressure to keep pupils quiet and lack of essential resources that could contribute to the development of learners' language, confidence and imaginative use of English.

It must be pointed out, however, that many of the classroom environment constraints and the issues of teacher proficiency and training are not limited to Sudan. Garton et al (2011) refer to several studies that raise the concern of teacher training, classroom methodologies and classroom environment issues in a number of locations. Their study considered teachers of young learners, $92 \%$ of whom are non-native and concluded similar to Sudan the vital importance of teacher training, both pre-service and in-service. Their recommendations are relevant to most young learner environments in developing situations.

\section{Conclusions and recommendations of the current study}

The workshop focused on two factors in the teaching and learning process: teachers and learners. The new textbook being developed was not under review but was the catalyst that generated focus on teacher training. While this was a short exploratory workshop certain clear signals emerged from the event that should be considered in the revision of English language teaching and the introduction of the language to young learners.

The concerns of the stakeholders must be taken into consideration in any changes in how English language is presented, developed and taught in the schools. It is important to remember today that English is a global language and does not have to come laden with a lot of cultural baggage. English is needed as the language of science, technology, medicine and academic life. The stakeholders in the current situation are:

- The students many of whose future employment prospects depend on a good working knowledge of English (Nur, 2006). Knowledge of English can now be classed as a basic skill requirement in the $21^{\text {st }}$ century (Graddol, 2007). The country's future depends on having highly qualified personnel in the fields of business, engineering, medicine, agriculture and technology. Whether we like it or not, English is still the medium in all of these areas.

- The teachers whose livelihood, reputations and future depend on being able to deliver what is expected of them. Attitudes towards the selection of teachers have to be revised so that only those who are capable of evolving into competent teachers should be selected. This means that the job of English Language Teaching must be made attractive to high achievers before entering university. Technology and the use of modern aids should be an essential part of teacher training and delivery of a course.

- Curriculum planners and developers whose professional personae depend on producing material that meets the needs of both students and teachers. Any curriculum development should be done keeping the needs of students, contextual constraints and teacher ability in mind. Attention should be given to a methodology that will help teachers deliver and students benefit from the material. Attention should also be directed to the possibility of producing locally made materials for teaching English to young learners. This would reduce the cost of importing expensive educational material and would also generate some local employment in the production of the materials.

- Education planners who are making decisions that will affect the three previous groups. These people need to develop regulations and systems as pointed out by Mohammed that will ensure effective delivery of courses. Mohammed also pointed out that attention has to be paid to the environment in which teacher training takes place and some attempt made to make the teaching/ learning space more conducive to success.

- Government which is providing the money, effort and time for the above endeavours. Effective and competent personnel, fluent in both Arabic and English are vital in the workplace.

- Private businesses in finance, management, education, engineering (Nur, 2006). They all need welleducated employees who will be able to keep abreast of recent developments in their chosen field of expertise. 


\section{Bibliography}

[1]. Baffoka, M. (2012). Changing teachers' views about teaching and learning: A pre-requisite for improving ELT and student proficiency in English in Sudanese universities. In Time for Change. London: British Council.

[2]. Bruner, J.S. (1960). The Process of Education. Cambridge, Mass: Harvard University Press.

[3]. Bruner, J.S. (1966) Toward a Theory of Instruction. Cambridge, Mass: Belkapp Press.

[4]. Cameron, L. (2001). Teaching Languages to Young Learners. Cambridge: CUP.

[5]. Espinosa, L.M. (2008). Challenging Common Myths about young English Language Learners. New York: Foundation Child Development.

[6]. Friere, P. (1972) Pedagogy of the Oppressed.Harmondsworth: PelicanGarton, S. , Copland, F. \& Burns, A. Burns. (2011) Investigating Global Practices in Teaching English to Young Learners. London: British Council. http://englishagenda.britishcouncil.org/sites/ec/files/B094\%20FINAL\%20Aston\%20University\%20A4\%20report_2column_V3.pdf

[7]. Graddol, D. (2007). Why global English may mean the end of 'English as a Foreign Language'http://www.britishcouncil.org/learning-research-english-next.pdf

[8]. Gumaa-Siddiek, A. (2011).Foreign Language Teacher Training in Sudan: Past, Present and Strategies for Future Recruitment Policies. International Journal of English Linguistics. Vol 1 No 2 Sept 2011.

[9]. Kincheloe, J.L. (2008). Knowledge and Critical Pedagogy: An Introduction. Dordecht, London: Springer.

[10]. Lenneberg, E.H. (1967). Biological Foundations of Language. Wiley.

[11]. Met, M., \& Rhodes, N. (1990). Priority: Instruction. Elementary school foreign language instruction: Priorities for the 1990s. Foreign Language Annals, 25, 433-43.

[12]. McLaughlin, B. (1992) Myths and misconceptions about second language learning: What every teacher needs to unlearn. The National Center for Research on Cultural Diversity and Second Language Learning. Educational Practice Report:5.

[13]. McLeod, S. A. (2009). Jean Piaget. Retrieved from http://www.simplypsychology.org/piaget.html

[14]. Mohammed, \& A/Ghani Ibrahim. (2009). Evaluation of Sudanese experience in teacher training. http://www.wrc.org.sd/tagweem.htm

[15]. Mohr, K \& Mohr, E. (2007). Extending English Language Learners' Classroom Interactions using Response Protocols. Retrieved from http://www.readingrockets.org/article/26871

[16]. Moon, J. (2005). Teaching English to Young Learners: the Challenges and the Benefits. Retrieved from http://www.britishcouncil.org/ie2005w30-jayne-moon.pdf

[17]. Nikolov, M \& Curtain, H. (2000). An Early Start: Young Learners and Modern Languages in Europe and Beyond. Council of Europe.

[18]. Nur, H.S. M. (2012). Time for Change: Developing English Language Teaching at Tertiary Level. In Time for Change. (2012). London: British Council.

[19]. O'Brien, J. (1988). Why Damn the Nile if the Generator is inadequate: an investigation into the use of the NILE course in the Sudanese Secondary School. Unpublished MA thesis.University of Birmingham.

[20]. O'Brien, J. (2013). English Language in Sudanese Schools - a way forward: delivered at Humanities and Educational Studies Conference, University of Khartoum, Sudan February 25 - 28, 2013

[21]. Piaget, J. (1928). Judgment and reasoning in the child. Paterson, NJ: Littlefield, Adams \& Co.

[22]. Piaget, J. (1952). The origins of intelligence in children. (M. Cook, Trans.). New York, NY: International University Press.

[23]. Taha, O.H.M. (1980). Sociological and Pedagogical Factors influencing the Teaching of English Language in the Sudan. Unpublished M.A. Thesis, University of Leeds School of Education

[24]. Tigani, M. el Tom, el (1966) The Role of English in the Sudan, Proceedings of the Conference held at Khartoum University 1966, pp. $9-25$, Khartoum.

[25]. Tuckman, B. \&Monetti, D. (2010). Educational Psychology. New York: Cengage.

[26]. Vygotsky, L. (1978). Interaction between Learning and Development.In Gauvain, M. \& M. Cole.Readings on the Development of Children. Freeman: New York. 